\title{
Temperature, Solid Loading and Time Effects on Recovery of Sugar from OPEFB
}

\author{
Diah Meilany ${ }^{1,2}$, MTAP Kresnowati ${ }^{2 *}$, and Tjandra Setiadi ${ }^{2}$ \\ ${ }^{1}$ Teknik Kimia, Politeknik Negeri Malang, Malang 65141, Indonesia \\ ${ }^{2}$ Teknik Kimia, Institut Teknologi Bandung, Bandung 40132, Indonesia
}

\begin{abstract}
Biorefinery industry used lignocellulosic biomass as the raw material. Oil Palm Empty Fruit Bunch (OPEFB) is one of Indonesian potential lignocellulosic biomass, which consists of hemicellulose with xylan as the main component. Xylitol production via fermentation could use this xylan since it can be converted into xylose. However, the structure of OPEFB is such that hemicellulose is protected in a way that will hinder hydrolysis enzyme to access it. Considering that hemicellulose is more susceptible to heat than cellulose, a hydrothermal process was applied to pre-treat OPEFB before it was hydrolyzed enzymatically. The aim of the research is to map the effect of temperature, solid loading and time of pre-treatment process to obtain and recover as much as possible accessible hemicellulose from OPEFB. The results showed that temperature gave more significant effect than time and solid loading for glucose recovery of OPEFB residues. While xylose recovery varies greatly with temperature, but solid loading and time gave less significant effect.
\end{abstract}

\section{Introduction}

OPEFB is one of lignocellulosic biomass that is well known as an industrial waste, especially in palm oil industry. Directorate General of Estate Crops of Indonesian Ministry of Agriculture estimated that 32.0 million tons of palm oil were produced in late 2016[1]. OPEFB as industrial waste reached 34.5 million tons but only about $23 \%$ utilized as mulch in palm oil plantation [2]. The rest of it will be pilled around the palm oil plant or plantation. This condition raises many problems in environmental such as methane production.

OPEFB is composed of cellulose $31-43 \%$, hemicellulose $23-35 \%$, and lignin $11-23 \%$ [3]-[5]. The hemicellulose content is promising enough to be utilized as one of xylose source for xylitol production. Hemicellulose is a polysaccharide composed mainly of xylan that is built-up of xylopyranose unit, connected by $1,4-\beta$ glucosidic linkage [6]. A process to depolymerize hemicellulose into xylose is by hydrolyzing xylan and this research focuses on using the biological way that is hydrolyzing OPEFB enzymatically.

There is a structural barrier in order to gain hemicellulose from OPEFB since hemicellulose is covered by lignin and is attached to cellulose fibril. Lignin cover will hinder enzyme to reach the hemicellulose since it is an amorphous polymer [7]. This makes it important to remove lignin from OPEFB by pre-treatment process.
There have been some efforts to pre-treat OPEFB on variety lignocellulosic biomass. It can be chemical pretreatment using a dilute acid such as reported applied on OPEFB [8], corn cob [9], Eucalyptus globulus chips [10], sunflower stalk and tobacco stalk [11]. Others use dilute base such as reported on OPEFB [12], bamboo [13], and wheat straw [14]. However, both acid and base pre-treatment produce a toxic compound that will disturb xylitol fermentation using wild strain yeast. Instead, a genetically modified strain was developed to omit the detoxification process [15]. Another method is the organosolv method such as used on Oil Palm fronds [16], wheat straw [17] the steam explosion on sugarcane bagasse [18], sugarcane straw [19], wheat straw [20], spruce wood chips [21]. These methods partially hydrolyzes lignin bond with cellulose and hemicellulose but most of the hemicellulose are solubilized [22]. The milder process is using a hydrothermal process such was used on OPEFB [23], prairie cordgrass [24], hardwood [25], seeds of Euterpe oleracea [26]. The uses of water as an agent to break the bond between lignin, cellulose, and hemicellulose is having mild effects on OPEFB residue.

Hemicellulose is more susceptible to heat than cellulose; thereby it needs a careful choice of pretreatment method and condition that will not solubilize hemicellulose. Acid or base will solubilize hemicellulose like a steam explosion. The hydrothermal process is a mild process but temperature chosen must be perfect.

\footnotetext{
"Corresponding author: kresnowati@che.itb.ac.id
} 
Besides, solid loading and time will affect the success of hemicellulose recovery too. This research study the effect of these three parameters in hemicellulose recovery measured as sugar (xylose) in OPEFB residues.

\section{Methods}

\subsection{Raw material}

OPEFB was kindly provided by PTPN VIII, Cigudeg, Bogor. It was cut into $10-12 \mathrm{~cm}$, washed with tap water and then dried in $60^{\circ} \mathrm{C}$ oven for 24 hours. Next, the OPEFB was milled and sieved into $-60+80$ mesh then stored in a ziplock bag before used.

The enzyme used was xylanase from China, in a powder form with an activity of 22,072.48 U/g. Xylose is purchased from Sigma-Aldrich while glucose is purchased from E-Merck as standard in HPLC analysis. Chemicals for citrate buffer was of p.a. grade, purchased from E-Merck.

\subsection{Experimental methods}

The experiments were conducted following a BoxBehnken design of experiment as presented in table 1.

Table 1 Box Behnken design of experiment

\begin{tabular}{|c|c|c|c|}
\hline $\begin{array}{c}\text { RUN } \\
\text { ORDER }\end{array}$ & SL & TEMP & TIME \\
\hline 1 & 5 & 165 & 15 \\
\hline 2 & 5 & 165 & 60 \\
\hline 3 & 5 & 165 & 15 \\
\hline 4 & 5 & 165 & 60 \\
\hline 5 & 10 & 165 & 37.5 \\
\hline 6 & 10 & 130 & 60 \\
\hline 7 & 15 & 130 & 37.5 \\
\hline 8 & 10 & 200 & 15 \\
\hline 9 & 15 & 165 & 60 \\
\hline 10 & 15 & 130 & 37.5 \\
\hline 11 & 10 & 130 & 60 \\
\hline 12 & 10 & 200 & 60 \\
\hline 13 & 5 & 200 & 37.5 \\
\hline 14 & 15 & 165 & 15 \\
\hline 15 & 10 & 165 & 37.5 \\
\hline 16 & 15 & 200 & 37.5 \\
\hline 17 & 5 & 130 & 37.5 \\
\hline 18 & 10 & 165 & 37.5 \\
\hline 19 & 10 & 200 & 15 \\
\hline 20 & 10 & 165 & 37.5 \\
\hline 21 & 15 & 165 & 15 \\
\hline 22 & 5 & 200 & 37.5 \\
\hline 23 & 15 & 165 & 60 \\
\hline 24 & 10 & 165 & 37.5 \\
\hline 25 & 5 & 130 & 37.5 \\
\hline 26 & 10 & 200 & 60 \\
\hline 27 & 10 & 165 & 37.5 \\
\hline 28 & 10 & 130 & 15 \\
\hline 29 & 15 & 200 & 37.5 \\
\hline 30 & 10 & 130 & 15 \\
\hline
\end{tabular}

The pretreatment experiments were conducted in a 100 $\mathrm{mL}$ autoclave equipped with paddle stirrer and stirrer cooler as shown in Fig 1.

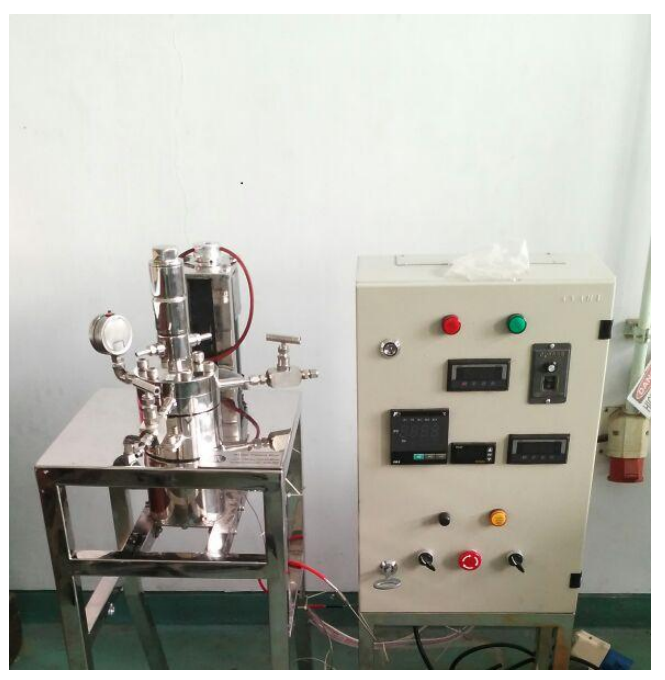

Fig. 1 High-pressure tank

The experiments were aimed to find the effect of temperature, solid loading and time on sugar recovery. The variables are the temperature of 130, 165 and $200^{\circ} \mathrm{C}$; solid loading of $5 \%, 10 \%$, and $15 \%$, and time of $15,37.5$ and 60 minutes. Each pre-treatment experiment used $50 \mathrm{~mL}$ of RO water.

After the pre-treatment process, the mixture was screened using fine mesh cloth and the solid residue was left in an oven at $50^{\circ} \mathrm{C}$ overnight. Before the further process, the supernatant was kept in a freezer to prevent contamination. Hydrolysis for solid residue was performed in a $100 \mathrm{~mL}$ Schott bottle at $5 \%$ of solid loading in an incubator shaker (Daihan Labtech.Co.Ltd).

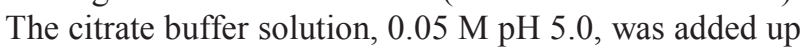
until working volume of $50 \mathrm{~mL}$.

Prior to the addition of enzyme, the mixture of OPEFB and buffer were autoclaved at $121^{\circ} \mathrm{C}$ for 15 minutes. Incubation was performed for 48 hours at $50^{\circ} \mathrm{C}$ and $150 \mathrm{rpm}$. Samples were centrifuged at $6000 \mathrm{rpm}$ for 15 minutes then filtered by $0.22 \mathrm{~mm}$ microfilter before sugar concentration analysis of the hydrolyzate.

Sugar concentration in hydrolyzate was analyzed using HPLC (Alliance HPLC System, Waters) using method developed by NREL [27]. Whole experiments were conducted in duplo and the error of each experiments were $15 \%$ maximum.

\section{Results}

The effects of temperature, solid loading and time on sugar recovery are shown on the graphs on fig. 2 to fig. 4 respectively.

\subsection{Temperature effect}

Temperature effects on sugar recovery are shown in fig. 2.a and 2.b 
a.
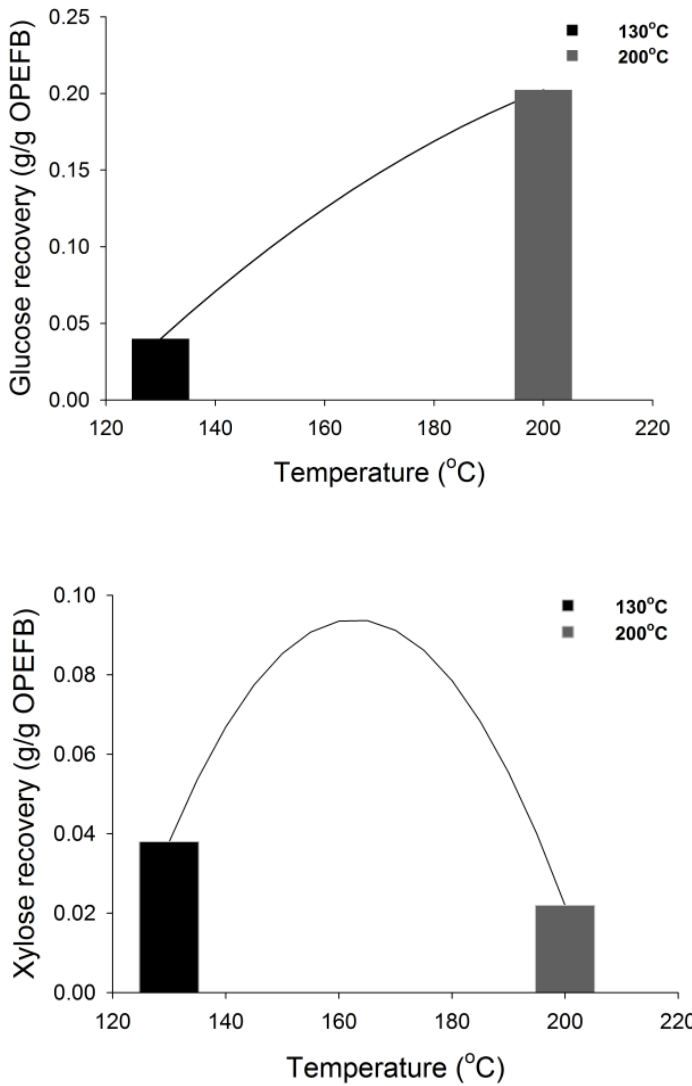

Fig. 2 Effects of temperature on sugar recovery: (a) glucose, (b) xylose. Experiments were conducted at solid loading 10\% and 60 minutes.

As can be seen on fig.2.a, Glucose recovery tends to raise as the temperature was increasing, unlike xylose recovery. When the temperature was higher than $130^{\circ} \mathrm{C}$, the xylose recovery was lowering significantly. The line curve represents sugar recovery as a function of temperature at $10 \%$ solid loading and 60 minutes pretreatment process. Glucose has not reached the maximum recovery although pre-treatment process had proceeded for 60 minutes, unlike xylose recovery that seems to reach a maximum at $165^{\circ} \mathrm{C}$.

This proves that hemicellulose is more susceptible to heat than cellulose. High temperature can solubilize hemicellulose, therefore, xylan cannot be used as xylose source. The high temperature of $200^{\circ} \mathrm{C}$ had been used in pre-treatment of sugarcane bagasse, sugarcane straw, wood and OPEFB resulted in that hemicellulose is solubilized [18], [19], [28], [29].

\subsection{Solid loading (SL) effects}

Solid loading effects on sugar recovery are shown in fig.3.a and 3.b.

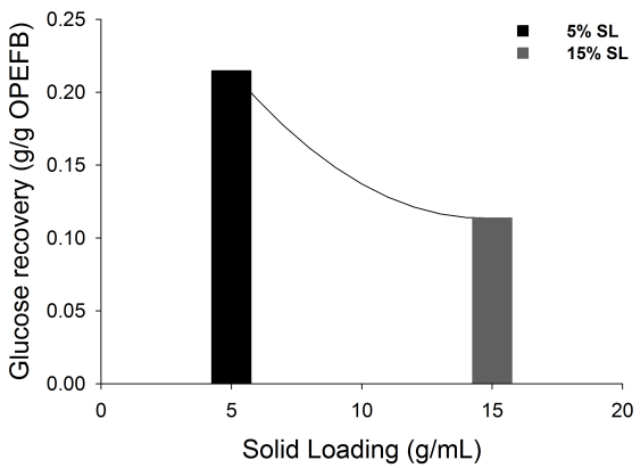

b.

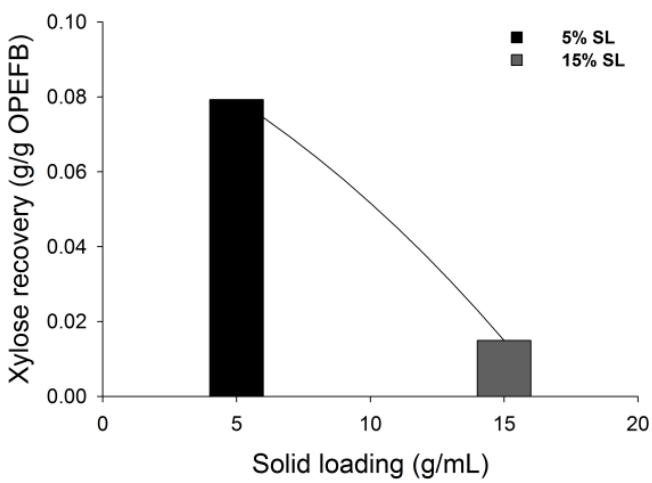

Fig. 3 Effects of pre-treatment solid loading on sugar recovery: (a) glucose, (b) xylose. Experiments were conducted at temperature $165^{\circ} \mathrm{C}$ and at pretreatment time of 60 minutes

The graphs on fig. 3.a and $b$ showed that the rise of SL will decrease the sugar recovery. This is true since a high solid loading will create a mechanical hindrance.

This experiment was using a $100 \mathrm{~mL}$ tank with paddle agitator. The $15 \% \mathrm{SL}$ in $50 \mathrm{~mL}$ mixture formed a compact mixture, makes it difficult to mix thoroughly. This condition leads to lowering glucose recovery more than xylose since there is not enough water molecule to interact with in order to break the lignin bonds with cellulose and hemicellulose. Furthermore, this data was taken at $165^{\circ} \mathrm{C}$ which is different with fig.2.a. The lower SL $(10 \% \mathrm{SL})$ at $200^{\circ} \mathrm{C}$ and 60 minutes gave higher glucose recovery. To overcome this, a specific reactor is needed [30].

\subsection{Time effects}

Time effects on sugar recovery are shown in fig. 4. Time here means time proceeded while heating the mixture at a certain temperature.

As can be seen in fig.4, a longer pre-treatment time will increase the sugar recovery. 


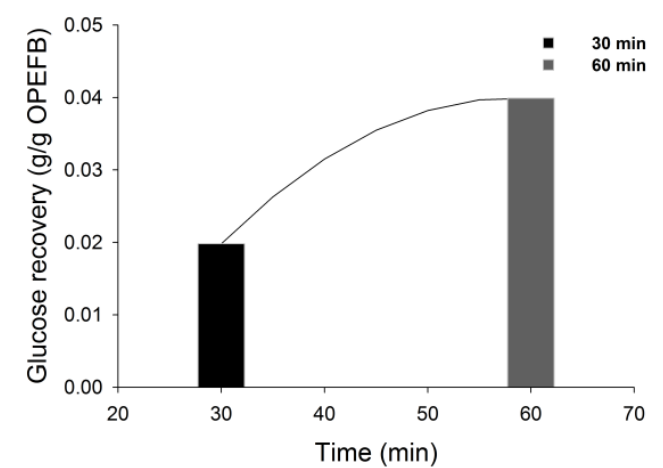

b.

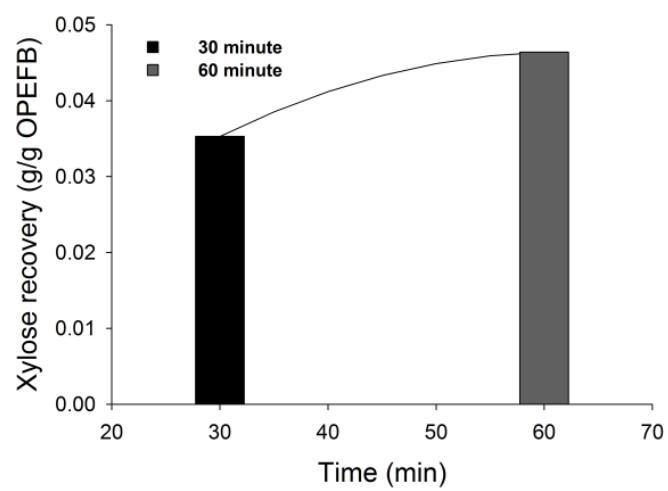

Fig. 4 Effect of pre-treatment time on sugar recovery: (a) glucose, (b) xylose. Experiments were conducted at solid loading $10 \%$ and a temperature of $130^{\circ} \mathrm{C}$

The graphs in fig. 4.a and 4.b showed that the increase of sugar recovery is affected by time although not significantly. As a comparison, OPEFB which was pre-treated using the hydrothermal process at $127.9^{\circ} \mathrm{C}$ for 60 and 90 minutes did not give a significant rise of xylose recovery [31].

Another result as shown in fig.2.a. glucose recovery is higher than in fig.4.a. It resulted from pre-treatment process at $200^{\circ} \mathrm{C}$;instead $10 \% \mathrm{SL}$ and 60 minutes time. It seems like temperature gave more significant effect on glucose recovery as to xylose recovery. This result leads to a hypothesis that there are one or more variables that give more significant effect to others, that is to be described in the section below.

\subsection{Statistical analysis of effects}

Statistical analysis was performed in order to describe the effects of three parameters on sugar recovery. Using main effects plot versus mean value of each sugar recovery, as shown in fig.5. a.

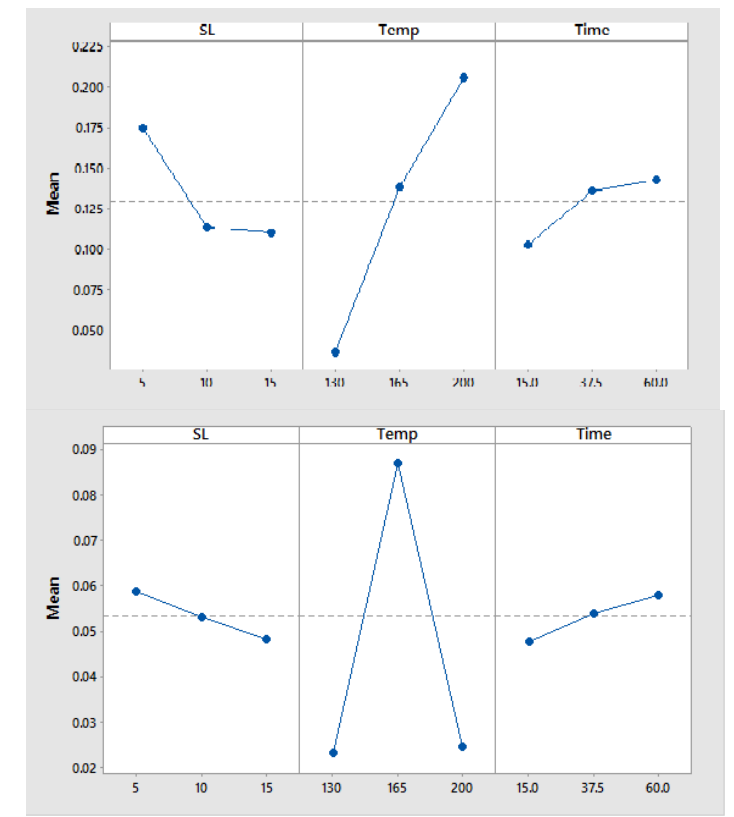

Fig. 5 Main effect plot on glucose (a) and xylose recovery (b)

Fig.5.a and $b$ show that a higher SL will reduce glucose and xylose recovery. The slope of glucose recovery is steeper, this means that SL will affect glucose recovery more significant than to xylose. Temperature shows that a higher temperature will increase glucose recovery. While for xylose recovery shows a great variety of temperature effect. Longer process time shows the same effect as temperature. Since the slope of glucose is steeper means that time gives more significant effect on glucose recovery.

Among these three variables, temperature shows the steepest slope, means that it gives more significant effect on sugar recovery, compared to solid loading and pretreatment time. There must be one perfect combination of these three variables to achieve a high recovery of sugar.

\section{Conclusion}

Despite this experiment limitation, the temperature has shown more significant effect than the other two, time and SL. Temperature and time will increase the sugar recovery while SL will decrease the sugar recovery.

\section{References}

1. I. M. E. Subiyantoro, \& Y. Arianto, Statistik Perkebunan Indonesia 2014 - 2016 Kelapa Sawit (Palm Oil). (2015).

2. R. Omar, A. Idris, R. Yunus, K. Khalid, \& M. I. A. Isma, Fuel, 90, 1536-1544 (2011).

3. S. Octavia, Pengolahan Awal Berbasis amoniak Terhadap Biomassa Lignoselulosik Bahan Mentah Pembuatan Bioetanol. (Institut Teknologi Bandung, 2013).

4. S. H. A. Rahman, J. P. Choudhury, \& A. L. Ahmad, Biochem. Eng. J. 30, 97-103 (2006).

5. M. Shibata, M. Varman, Y. Tono, H. Miyafuji, \& S. Saka, J. Jpn. Inst. Energy, 87, 383-388 (2008). 
6. Chen, H. Biotechnology of lignocellulose: Theory and practice. (Springer Netherlands, 2014).

7. G. Brodeur, et al. Enzyme Research (2011). doi:10.4061/2011/787532

8. S. Duangwang, T. Ruengpeerakul, B. Cheirsilp, R. Yamsaengsung, \& C. Sangwichien, Bioresour. Technol., 203, 252-258 (2016).

9. F.-Q. Wang, et al. Bioresour. Technol., 144, 572578 (2013)

10. A. Converti, J. M. Domínguez, P. Perego, S. S. da Silva, \& M. Zilli, Chem. Eng. Technol., 23, 10131020 (2000).

11. O. Akpinar, O. Levent, S. Sabanci, R. S. Uysal, \& B. Sapci, Bio. Resources 6, 4103-4116 (2011).

12. N. Zulkiple, M. Y. Maskat, \& O. Hassan, Mol. Cell. Life Sci. Infect. Dis. Biochem. Struct. Biol. 2015 Conf., 18, 155-161 (2016).

13. S. X. Chen, Z. D. Wang, K. Fang, G. R. Fan, \& P. Wang, Adv. Mater. Res., 1033-1034, 114-118 (2014).

14. M. C. Coimbra, et al. Renew. Energy, 86, 10601068 (2016).

15. E. Hong, et al. Biotechnol. Bioprocess Eng., 21, 612-619 (2016).

16. C. Ofori-Boateng, \& K. T. Lee, Fuel, 115, 170-178 (2014).

17. H. Chen, J. Zhao, T. Hu, X. Zhao, \& D. Liu, Appl. Energy, 150, 224-232 (2015).

18. R. Biswas, H. Uellendahl, \& B. K. Ahring, Biomass Bioenergy, 61, 104-113 (2014).

19. F. M. V. Oliveira, et al. Bioresour. Technol. 130, 168-173 (2013).

20. P. Alvira, M. J. Negro, I. Ballesteros, A. González, \& M. Ballesteros, Bioethanol, 2, 66-75 (2016).

21. T. Pielhop, J. Amgarten, P. R. von Rohr, \& M. H. Studer, Biotechnol. Biofuels, 9, 152 (2016).

22. D. K. Sidiras, \& I. S. Salapa, Biorefinery I: Chemicals and Materials From Thermo-Chemical Biomass Conversion and Related Processes (ECI Symposium Series, 2015).

23. M. B. Harahap, Evaluasi Konfigurasi Proses Produksi Xilitol dan Etanol dari Tandan Kosong Kelapa Sawit Secara Terintegrasi. (Institut Teknologi Bandung, 2016).

24. H. Lei, I. Cybulska, \& J. Julson, J. Sustain. Bioenergy Syst., 3, 250-259 (2013).

25. C. K. Nitsos, T. Choli-Papadopoulou, K. A. Matis, \& K. S. Triantafyllidis, ACS Sustain. Chem. Eng., 4, 4529-4544 (2016).

26. A. R. Oliveira, J., Komesu, A. \& Maciel Filho, R. Chem. Eng. Trans., 37, 787-792 (2014).

27. A. Sluiter, et al. Determination of Sugars, Byproducts, and Degradation Products in Liquid Fraction Process Samples in Laboratory Analytical Procedure. (2008).

28. A. P. Nunes, \& J. Pourquie, Bioresour. Technol., 57, 107-110 (1996).

29. J. D. C. Medina, et al., Bioresour. Technol., 199, 173-180 (2016).

30. J. Zhang, W. Hou, \& J. Bao, Bioreactor Engineering Research and Industrial Applications
II, 75-90 (Springer, Berlin, Heidelberg, 2015). doi:10.1007/10 2015307

31. M. B. Harahap \& M. T. A. P. Kresnowati, Biomass Convers. Biorefinery, (2017). 